\title{
Avaliação da Aptidão Física em Idosos
}

Vicente, S. ${ }^{1}$, Faustino, A. ${ }^{2}$, Serrano, J. ${ }^{2}$ y Batista, M. ${ }^{2}$

1 Municipio de Pampilhosa da Serra; email: profefsamuel@gmail.com 2 Instituto Politécnico de Castelo Branco Email: a.faustino@ipcb.pt

RESUMO: O presente estudo tem como objetivo principal conhecer a aptidão física funcional em dois grupos distintos de idosos (praticantes e não praticantes de atividade física organizada) do concelho de Pampilhosa da Serra. Saber se há diferenças ao nível da aptidão física entre um grupo que praticou atividade física organizada durante 9 meses (2x semana) e um grupo que não praticou e ainda saber se há diferenças ao nível da aptidão física entre os grupos de ginástica sénior das diferentes freguesias. A amostra foi constituída por 225 idosos com idades entre os 65 e 94 anos de idade. Na recolha de dados foi aplicada a bateria de testes Senior Fitness Test (Rikli y Jones, 2001). Os resultados demonstraram que os praticantes que tiveram atividade física organizada apresentaram em todos os testes melhores níveis de aptidão física. Entre os dois grupos encontrámos diferenças estatisticamente significativas em todas as provas aplicadas. Concluimos que a prática de atividade física organizada teve um impacto positivo na aptidão física dos idosos avaliados.

PALABRAS CHAVE: Envelhecimento, Gerontomotricidade, Atividade Física, Qualidade de Vida, Aptidão Física.

\section{Assessment of Physical Fitness in the Elderly}

ABSTRACT: This study aims to identify the functional fitness in two different age groups (practitioners and non-practitioners of organized physical activity) from Pampilhosa da Serra municipality. Whether there are differences in terms of physical fitness among a group who practiced physical activity organized for 9 months ( $2 x$ semana) and a group that did not practice and also whether there are differences in terms of physical fitness among senior gymnastics groups from different parishes. The sample consisted of 225 elderly people aged between 65 and 94 years old. Collecting data was applied to a battery Senior fitness test tests (Kikli y Jones, 2001). The main results showed that the organized physical activity practitioners had in all tests better fitness levels than non-practitioners. Between the two groups found statistically significant differences in all applied tests. We conclude that the practice of organized physical activity has a positive impact on the physical fitness of the elderly evaluated.

KEY WORDS: Aging, gerontomotricity, Physical Activity, Quality of Life, Physical Fitness. 


\section{INTRODUÇÃO}

$\mathrm{Na}$ atualidade, os idosos são cada vez mais um grupo social que atrai a atenção dos indivíduos e da comunidade científica (investigadores), muito devido à esperança média de vida ter aumentado de forma significativa, são necessários esforços para compreender e investigações na área que permitam um melhor entendimento da sua situação.

Os indicadores sociais apontam para um envelhecimento populacional ao nível europeu, assistimos atualmente a uma diminuição da taxa de natalidade e mortalidade, afetando diretamente a população ativa, que diminui $13 \%$ em relação ao trimestre homólogo de 2013, correspondendo a 66,4 mil indivíduos (INE, dados estatísticos de Emprego 2014, 1. trimestre).

A população residente em Portugal, em 31 de dezembro de 2014, foi estimada em 10374822 de indivíduos, o que significou uma diminuição de $-0,5 \%$ face ao valor estimado para o ano anterior, mantendo, assim, a tendência negativa de crescimento populacional registada nos quatro anos anteriores (-0,1\%, entre 2009 e $2010,-0,3 \%$ entre 2010 e 2011, -0,5\% entre 2011 e 2012, e -0,6\% entre 2012 e 2013). (INE, 2015). Em paralelo, assistimos ainda um decréscimo da população ativa e ao acréscimo da população reformada, que só na região centro, encontramos uma população de 591,670 de um total de 2,339,094 (INE, dados dos censos de 2011).

Com a intenção de promover a atividade física organizada no concelho de Pampilhosa da Serra, mostrando aos cidadãos alguns benefícios que esta tem na aptidão física funcional, o presente estudo tem como tema "Avaliação da Aptidão Física em Idosos".

O objetivo principal do estudo foi avaliar a aptidão física funcional em idosos praticantes e não praticantes de atividade física organizada, tendo em conta que os utentes praticantes têm duas aulas por semana ao longo de 9 meses. Ainda foi realizada uma comparação entre os 8 grupos de ginástica sénior, no sentido de perceber qual a turma que tem melhores níveis de aptidão física funcional.

A amostra foi constituída por 225 idosos com idades compreendidas entre 65 e 97 anos de idade, residentes no concelho de Pampilhosa da Serra. Para avaliar a aptidão física funcional a amostra foi dividida em 2 grandes grupos (156 praticantes de atividade física organizada e 69 não praticantes de atividade física organizada.) e 0 grupo de praticantes de atividade física organizada em 8 subgrupos (grupos de ginástica sénior).

Na recolha de dados foi aplicado a bateria de testes Senior Fitness Test (Rikli y Jones, 2001), que tem a finalidade de avaliar a aptidão física funcional, a qual foi aplicada pelo investigador seguindo o protocolo de provas, sendo os testes aplicados em salas adequadas e pela mesma ordem nos dois grupos (praticantes e não praticantes). A análise estatística dos dados foi realizada através do software SPSS versão 23.0 . 


\subsection{Justificação do estudo}

Devido ao envelhecimento acentuado da população no concelho de Pampilhosa da Serra ${ }^{1}$, surge a necessidade de avaliar se a atividade física organizada tem um impacto substancial, por forma a melhorar os níveis de aptidão física dos idosos, com isto consideramos pertinente fazer uma comparação entre os grupos de idosos praticantes de atividade física organizada (utentes da ginástica sénior) e, por sua vez, uma comparação entre estes e os que não praticam atividade física organizada. E por este motivo, importa investigar sobre como envelhecer com qualidade de vida e quais os contributos da prática da Atividade Física Organizada nesta faixa etária.

\subsection{Objetivo Geral}

O objetivo geral do nosso estudo foi conhecer a aptidão física funcional dos idosos do concelho da Pampilhosa da Serra e, saber se há diferenças ao nível da aptidão física entre um grupo que praticou atividade física organizada durante 9 meses (2xsemana) e um grupo que não praticou e ainda saber se há diferenças ao nível da aptidão física entre os grupos de ginástica sénior das diferentes freguesias.

\subsection{Objetivos Específicos}

Avaliar a aptidão física de um grupo de idosos submetidos à prática de atividade física organizada do concelho de Pampilhosa da Serra.

Avaliar a aptidão física de um grupo de idosos não submetidos à prática de atividade física organizada do concelho de Pampilhosa da Serra.

Comparar a aptidão física funcional de um grupo de idosos praticantes e de um grupo de idosos não praticantes de atividade física organizada, do concelho de Pampilhosa da Serra para verificar se existem diferenças significativas entre eles.

Comparar os resultados da aptidão física funcional do grupo de idosos praticantes de atividade física organizada das diferentes freguesias de Pampilhosa da Serra, para saber se existem diferenças significativas nos resultados.

\subsection{Hipóteses do estudo}

Hipótese 1, há diferenças estatisticamente significativas na aptidão física funcional entre o grupo de idosos praticantes de atividade física organizada e o grupo de idosos não praticantes de atividade física organizada.

Hipótese 2, há diferenças estatisticamente significativas na aptidão física funcional dos praticantes de atividade física organizada entre as diferentes freguesias do concelho de Pampilhosa da Serra.

\footnotetext{
${ }^{1}$ Localidade onde um dos autores exerce a sua atividade profissional.
} 


\section{MÉTODO}

\subsection{Amostra}

A participação no estudo foi realizada de forma voluntária. A amostra foi constituída por 225 idosos com idades compreendidas entre 65 e 97 anos de idade, residentes no concelho de Pampilhosa da Serra. Para avaliar a aptidão física funcional a amostra foi dividida em 2 grandes grupos (156 praticantes de atividade física organizada e 69 não praticantes de atividade física organizada). O grupo de praticantes de atividade física organizada pertence a 8 freguesias (grupos de ginástica sénior).

Tabela 1. Amostra

\begin{tabular}{|c|c|c|c|}
\hline Nível de atividade & Freguesia & Frequência & Percentagem (\%) \\
\hline \multirow{9}{*}{ Praticantes } & Cabril & 20 & 8,9 \\
\hline & Dornelas & 20 & 8,9 \\
\hline & Fajão-Vidual & 22 & 9,8 \\
\hline & Janeiro de Baixo & 23 & 10,2 \\
\hline & $\begin{array}{lll}\text { Portela do Fojo- } \\
\text { Machio }\end{array}$ & 29 & 12,9 \\
\hline & $\begin{array}{l}\text { Pampilhosa da } \\
\text { Serra }\end{array}$ & 8 & 3,6 \\
\hline & Pessegueiro & 28 & 12,4 \\
\hline & Unhais-o-Velho & 6 & 2,7 \\
\hline & Total & 156 & 69,3 \\
\hline Não praticantes & Total & 69 & 30,7 \\
\hline Total & & 225 & 100,0 \\
\hline
\end{tabular}

\subsection{Instrumentos}

Tendo em conta os nossos objetivos de estudo, para avaliar os níveis de aptidão física foram aplicados 7 testes da bateria de testes de Rikli y Jones (2001). A bateria de testes Senior Fitness Test (Rikli y Jones, 2001), consiste num conjunto de testes concebidos para avaliar parâmetros físicos associados à mobilidade e funcionamento autónomos em idades compreendidas entre os 60 e 94 anos. Com esta bateria de testes podemos avaliar a composição corporal, a força, a flexibilidade, o equilíbrio dinâmico e agilidade, a resistência aeróbia e a coordenação (Rikli y Jones, 2001).

No presente estudo os testes aplicados foram os seguintes:

\subsubsection{Composição corporal - IMC}

\subsubsection{Objetivo}

Avaliar o índice de massa corporal (Kg/m2). 


\subsubsection{Equipamento necessário}

Uma balança, uma fita métrica de $150 \mathrm{~cm}$, uma régua e um marcador.

\subsubsection{Calçado}

Por uma questão de tempo, as pessoas podiam estar calçadas durante a medição da altura e do peso, efetuando-se os ajustamentos abaixo descritos para correção do resultado. Recomendou-se todavia que esta avaliação seja realizada com o participante descalço.

\subsubsection{Descrição}

Estatura: Aplicar verticalmente contra uma parede uma fita métrica de $150 \mathrm{~cm}$, com o zero a $50 \mathrm{~cm}$ acima do solo. O participante encontra-se em pé encostado contra uma parede, olhando em frente, com a parte média da cabeça alinhada com a fita métrica. $\mathrm{O}$ avaliador coloca a régua nivelada sobre a cabeça do participante, de forma a tocar na fita métrica da parede. A estatura é a medida $(\mathrm{cm})$ indicada na fita métrica mais $50 \mathrm{~cm}$ (distância a partir do solo até ao zero da fita métrica). Caso o participante se encontre calçado, é necessário reduzir ao valor avaliado 1,3 a 2,5 cm.

Peso: O participante deve despir todas as peças de vestuário pesadas, tais como casacos, camisolas grossas. O peso é medido e registado com aproximação às $100 \mathrm{~g}$ e ajustamentos relativos ao peso do calçado. Em geral deve ser subtraído 0,45 $\mathrm{Kg}$ para mulheres e 0,91 Kg para homens.

\subsubsection{Avaliação e classificação}

A classificação é obtida tendo em conta a tabela 2.

Tabela 2. Classificação do Índice de Massa Corporal

\begin{tabular}{cc} 
IMC $\left(\mathbf{K g} / \mathbf{m}^{2}\right)$ \\
Défice de peso & $\leq 18 \mathrm{Kg} / \mathrm{m}^{2}$ \\
\hline Intervalo saudável & $19-26 \mathrm{Kg} / \mathrm{m}^{2}$ \\
\hline Excesso de peso & $\geq 27 \mathrm{Kg} / \mathrm{m}^{2}$ \\
\hline
\end{tabular}

Nota Fonte: Rikli, E. y Jones, J. (2001). Senior Fitness Test Manual. Champaign, IL: Human Kinetics.

\subsubsection{Levantar e sentar na cadeira}

\subsubsection{Objetivo}

O teste "levantar e sentar na cadeira" tem como objetivo avaliar a força e resistência dos membros inferiores.

\subsubsection{Equipamento necessário}

Cronómetro e uma cadeira com encosto (sem braços), com altura do assento de aproximadamente 43 centímetros.

\subsubsection{Descrição}


Por questões de segurança, a cadeira deve ser colocada contra uma parede ou estabilizada de qualquer outro modo, de forma a evitar que se mova durante a execução do teste.

O teste inicia-se com o participante sentado no meio da cadeira, com as costas direitas e os pés afastados à largura dos ombros e totalmente apoiados no solo. Um dos pés deve estar ligeiramente avançado em relação ao outro para ajudar a manter o equilíbrio. Os membros superiores devem estar cruzados ao nível dos pulsos e contra o peito. Ao sinal de "partida" o participante eleva-se até à extensão máxima (posição vertical) e regressa à posição inicial (sentado). O participante deve ser encorajado a completar o máximo de repetições num intervalo de tempo de 30 segundos. Enquanto é controlado o desempenho do participante para assegurar o maior rigor, o avaliador conta as elevações corretas. Podem ser realizadas chamadas de atenção verbais ou gestuais com o objetivo de corrigir o desempenho do avaliado. Após uma demonstração realizada pelo avaliador, o participante pode realizar um ou dois ensaios visando uma execução correta.

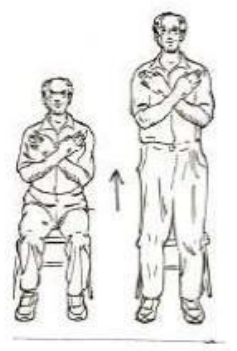

Figura 1 - Teste levantar e sentar na cadeira (Rikli y Jones, 2001).

\subsubsection{Avaliação e classificação}

Em relação à avaliação, a mesma é obtida pelo número de execuções corretas num intervalo de tempo de 30 segundos, caso o participante esteja a meio da elevação no final dos 30 segundos, esta deve contar como uma elevação correta. Finalmente, a classificação é realizada tendo em conta as tabelas 3 e 4.

Tabela 3. Classificação do teste levantar e sentar na cadeira em homens

\begin{tabular}{lccccccc} 
Classificação: & $\begin{array}{c}\mathbf{6 0 - 6 4} \\
\text { anos de } \\
\text { (homens) }\end{array}$ & $\begin{array}{c}\mathbf{6 5 - 6 9} \\
\text { anos de } \\
\text { idade }\end{array}$ & $\begin{array}{c}\mathbf{7 0 - 7 4} \\
\text { inos de } \\
\text { idade }\end{array}$ & $\begin{array}{c}\mathbf{7 5 - 7 9} \\
\text { anos de } \\
\text { idade }\end{array}$ & $\begin{array}{c}\mathbf{8 0 - 8 4} \\
\text { anos de } \\
\text { idade }\end{array}$ & $\begin{array}{c}\mathbf{8 5 - 8 9} \\
\text { anos de } \\
\text { idade }\end{array}$ & $\begin{array}{c}\mathbf{9 0 - 9 4} \\
\text { anos de } \\
\text { idade }\end{array}$ \\
\hline Muito fraco & $\leq 13$ & $\leq 11$ & $\leq 11$ & $\leq 10$ & $\leq 9$ & $\leq 7$ & $\leq 7$ \\
\hline Fraco & $14-15$ & $12-14$ & $12-13$ & $11-13$ & $10-11$ & $8-10$ & $8-9$ \\
\hline Regular & $16-17$ & $15-16$ & $14-16$ & $14-15$ & $12-13$ & $11-12$ & $10-11$ \\
\hline Bom & $18-20$ & $17-19$ & $17-18$ & $16-18$ & $14-16$ & $13-15$ & $12-13$ \\
\hline Muito bom & $\geq 21$ & $\geq 20$ & $\geq 19$ & $\geq 19$ & $\geq 17$ & $\geq 16$ & $\geq 14$ \\
\hline
\end{tabular}

Nota Fonte: Rikli, E. y Jones, J. (2001). Senior Fitness Test Manual. Champaign, IL: Human Kinetics. 
Tabela 4. Classificação do teste levantar e sentar na cadeira em mulheres

\begin{tabular}{lcccccccc}
$\begin{array}{l}\text { Classificação: } \\
\text { (mulheres) }\end{array}$ & $\begin{array}{c}\mathbf{6 0 - 6 4} \\
\text { anos de } \\
\text { idade }\end{array}$ & $\begin{array}{c}\mathbf{6 5 - 6 9} \\
\text { anos de } \\
\text { idade }\end{array}$ & $\begin{array}{c}\mathbf{7 0 - 7 4} \\
\text { anos de } \\
\text { idade }\end{array}$ & $\begin{array}{c}\mathbf{7 5 - 7 9} \\
\text { anos de } \\
\text { idade }\end{array}$ & $\begin{array}{c}\mathbf{8 0 - 8 4} \\
\text { anos de } \\
\text { idade }\end{array}$ & $\begin{array}{c}\mathbf{8 5 - 8 9} \\
\text { anos de } \\
\text { idade }\end{array}$ & $\begin{array}{c}\mathbf{9 0 - 9 4} \\
\text { anos de } \\
\text { idade }\end{array}$ \\
\hline Muito fraco & $\leq 12$ & $\leq 12$ & $\leq 11$ & $\leq 10$ & $\leq 10$ & $\leq 9$ & $\leq 8$ \\
\hline Fraco & $13-15$ & $13-14$ & $12-13$ & $11-13$ & $11-12$ & $10-11$ & $9-10$ \\
\hline Regular & $16-17$ & $15-16$ & $14-16$ & $13-15$ & $13-14$ & $12-13$ & $11-12$ \\
\hline Bom & $18-20$ & $17-19$ & $17-18$ & $16-18$ & $15-16$ & $14-15$ & $12-15$ \\
\hline Muito bom & $\geq 21$ & $\geq 20$ & $\geq 19$ & $\geq 19$ & $\geq 17$ & $\geq 16$ & $\geq 16$ \\
\hline
\end{tabular}

Nota Fonte: Rikli, E. y Jones, J. (2001). Senior Fitness Test Manual. Champaign, IL: Human Kinetics.

\subsubsection{Flexão do antebraço}

\subsubsection{Objetivo}

O teste "flexão do antebraço" tem como objetivo avaliar a força e resistência dos membros superiores.

\subsubsection{Equipamento necessário}

Um cronómetro, uma cadeira com encosto (sem braços), com altura do assento de aproximadamente 43 centímetros e um haltere de mão $(2,27 \mathrm{~kg}$ para as mulheres e 3,36 kg para os homens).

\subsubsection{Descrição}

Por questões de segurança, a cadeira deve ser colocada contra uma parede ou estabilizada de qualquer outro modo, de forma a evitar que se mova durante a execução do teste.

O teste inicia-se com o participante sentado numa cadeira, com as costas direitas, com os pés totalmente assentes no solo e com o tronco totalmente encostado na cadeira. $O$ haltere deve estar seguro na mão dominante. $O$ teste inicia-se com 0 antebraço em posição inferior, ao lado da cadeira, perpendicular ao solo. Ao sinal de "partida" o participante deve rodar gradualmente a palma da mão para cima, enquanto faz a flexão do antebraço no sentido completo do movimento, depois regressa à posição inicial de extensão do antebraço. O avaliador deve estar junto ao participante no lado do braço dominante, colocando os seus dedos no bicípite do executante, de modo a estabilizar a parte superior do braço, e assegurar que seja realizada uma flexão completa, o antebraço do participante deve apertar os dedos do avaliador. A parte superior do braço deve permanecer estática durante todo o teste.

O avaliador pode ter a necessidade de colocar a sua outra mão atrás do cotovelo de forma que o executante saiba quando atinge a extensão total, evitando assim movimentos de balanço do antebraço. O relógio deve ser colocado de forma totalmente visível. O participante deve ser encorajado a realizar o maior número de flexões possíveis num período de tempo de 30 segundos, mas sempre com movimentos controlados, tanto na fase de flexão como na fase de extensão. $O$ avaliador deverá acompanhar as execuções de forma a assegurar que o peso é transportado em toda a amplitude do movimento, da extensão total à flexão total. São contabilizadas todas as flexões corretas, sempre que se verificarem execuções 
incorretas, o avaliador deve fazer chamadas de atenção verbais. O participante deve realizar um ou dois ensaios após o avaliador fazer a demonstração.

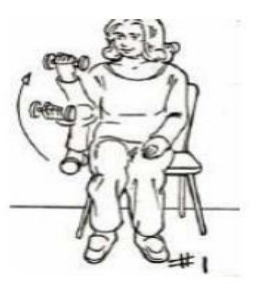

Figura 2 - Teste flexão do antebraço (Rikli y Jones, 2001).

\subsubsection{Avaliação e classificação}

A avaliação é obtida pelo número total de flexões corretas realizadas durante um período de tempo de 30 segundos. Se no final dos 30 segundo o antebraço estiver a meio da flexão, deve ser contabilizada como uma flexão total. Quanto à classificação a mesma é obtida tendo em conta as tabelas 5 e 6 .

Tabela 5. Classificação do teste flexão do antebraço em homens

\begin{tabular}{lcccccccc} 
Classificação: & $\begin{array}{c}\mathbf{6 0 - 6 4} \\
\text { anos de } \\
\text { (homens) }\end{array}$ & $\begin{array}{c}\mathbf{6 5 - 6 9} \\
\text { anos de } \\
\text { idade }\end{array}$ & $\begin{array}{c}\mathbf{7 0 - 7 4} \\
\text { anos de } \\
\text { idade }\end{array}$ & $\begin{array}{c}\mathbf{7 5 - 7 9} \\
\text { anos de } \\
\text { idade }\end{array}$ & $\begin{array}{c}\mathbf{8 0 - 8 4} \\
\text { anos de } \\
\text { idade }\end{array}$ & $\begin{array}{c}\mathbf{8 5 - 8 9} \\
\text { anos de } \\
\text { idade }\end{array}$ & $\begin{array}{c}\text { 90-94 } \\
\text { anos de } \\
\text { idade }\end{array}$ \\
\hline Muito fraco & $\leq 15$ & $\leq 14$ & $\leq 13$ & $\leq 12$ & $\leq 12$ & $\leq 10$ & $\leq 9$ \\
\hline Fraco & $16-18$ & $15-17$ & $14-16$ & $13-15$ & $13-15$ & $11-13$ & $10-11$ \\
\hline Regular & $19-20$ & $18-20$ & $17-19$ & $16-17$ & $15-17$ & $14-15$ & $12-13$ \\
\hline Bom & $21-23$ & $21-23$ & $20-22$ & $18-20$ & $18-20$ & $16-17$ & $14-15$ \\
\hline Muito bom & $\geq 24$ & $\geq 24$ & $\geq 23$ & $\geq 21$ & $\geq 21$ & $\geq 18$ & $\geq 16$ \\
\hline
\end{tabular}

Nota Fonte: Rikli, E. y Jones, J. (2001). Senior Fitness Test Manual. Champaign, IL: Human Kinetics.

Tabela 6. Classificação do teste flexão do antebraço em mulheres

\begin{tabular}{lcccccccc}
$\begin{array}{l}\text { Classificação: } \\
\text { (mulheres) }\end{array}$ & $\begin{array}{c}\mathbf{6 0 - 6 4} \\
\text { anos de } \\
\text { idade }\end{array}$ & $\begin{array}{c}\mathbf{6 5 - 6 9} \\
\text { anos de } \\
\text { idade }\end{array}$ & $\begin{array}{c}\mathbf{7 0 - 7 4} \\
\text { anos de } \\
\text { idade }\end{array}$ & $\begin{array}{c}\mathbf{7 5 - 7 9} \\
\text { anos de } \\
\text { idade }\end{array}$ & $\begin{array}{c}\mathbf{8 0 - 8 4} \\
\text { anos de } \\
\text { idade }\end{array}$ & $\begin{array}{c}\mathbf{8 5 - 8 9} \\
\text { anos de } \\
\text { idade }\end{array}$ & $\begin{array}{c}\mathbf{9 0 - 9 4} \\
\text { anos de } \\
\text { idade }\end{array}$ \\
\hline Muito fraco & $\leq 13$ & $\leq 11$ & $\leq 11$ & $\leq 10$ & $\leq 9$ & $\leq 7$ & $\leq 6$ \\
\hline Fraco & $14-15$ & $12-14$ & $12-14$ & $11-13$ & $10-11$ & $8-10$ & $7-9$ \\
\hline Regular & $16-18$ & $15-17$ & $15-16$ & $14-16$ & $12-14$ & $11-13$ & $10-11$ \\
\hline Bom & $19-21$ & $18-20$ & $17-19$ & $17-18$ & $15-17$ & $14-16$ & $12-14$ \\
\hline Muito bom & $\geq 22$ & $\geq 21$ & $\geq 20$ & $\geq 19$ & $\geq 18$ & $\geq 17$ & $\geq 15$ \\
\hline
\end{tabular}

Nota Fonte: Rikli, E. e Jones, J. (2001). Senior Fitness Test Manual. Champaign, IL: Human Kinetics. 


\subsubsection{Sentado e alcançar}

\subsubsection{Objetivo}

O teste "sentado e alcançar" tem como objetivo avaliar a flexibilidade do tronco e dos membros inferiores.

\subsubsection{Equipamento necessário}

Uma cadeira com encosto com uma altura aproximada de $43 \mathrm{~cm}$. Por razões de segurança, a cadeira foi colocada contra uma parede e uma régua de 45 centímetros.

\subsubsection{Descrição}

O teste inicia-se com o participante sentado no bordo anterior do assento. Com uma perna fletida e o pé totalmente apoiado no solo, a outra perna (de preferência) é estendida com o pé em flexão a 90o. O movimento foi efetuado lentamente, com a cabeça no prolongamento da coluna, deslizando as mãos (uma sobre a outra com as pontas dos dedos sobrepostas) ao longo da perna estendida, em direção à ponta do pé. A posição final foi mantida durante 2 segundos sem fletir o joelho. Após demonstração por parte do avaliador, o mesmo questionou o participante sobre a perna preferida. Após um ou dois ensaios o participante iniciou o teste.

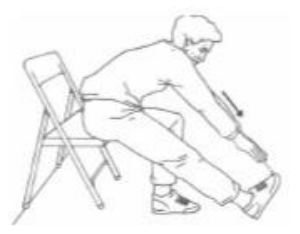

Figura 3 - Teste sentar e alcançar (Rikli y Jones, 2001).

\subsubsection{Avaliação e classificação}

O avaliador usou uma régua de $45 \mathrm{~cm}$ registou a distância $(\mathrm{cm})$ até a ponta do pé (resultado negativo), ou para além da ponta do pé (resultado positivo), que representando este ponto o zero. O melhor resultado de duas execuções é usado para avaliar o desempenho. A classificação é realizada tendo em conta as tabelas 7 e 8.

Tabela 7. Classificação do teste sentado e alcançar em homens

\begin{tabular}{|c|c|c|c|c|c|c|c|}
\hline $\begin{array}{l}\text { Classificação: } \\
\text { (homens) }\end{array}$ & $\begin{array}{c}60-64 \\
\text { anos de } \\
\text { idade }\end{array}$ & $\begin{array}{c}65-69 \\
\text { anos de } \\
\text { idade }\end{array}$ & $\begin{array}{c}70-74 \\
\text { anos de } \\
\text { idade }\end{array}$ & $\begin{array}{c}75-79 \\
\text { anos de } \\
\text { idade }\end{array}$ & $\begin{array}{c}\mathbf{8 0 - 8 4} \\
\text { anos de } \\
\text { idade }\end{array}$ & $\begin{array}{c}85-89 \\
\text { anos de } \\
\text { idade }\end{array}$ & $\begin{array}{c}90-94 \\
\text { anos de } \\
\text { idade }\end{array}$ \\
\hline Muito fraco & $\leq-3,4$ & $\leq-3,9$ & $\leq-3,9$ & $\leq-5,0$ & $\leq-6,2$ & $\leq-5,9$ & $\leq-7,2$ \\
\hline Fraco & $-3,3--0,6$ & $-3,8_{-}-1,1$ & $-3,8_{-}-1,2$ & $-4,9-2,3$ & $-6,1_{-}-3,2$ & $-5,8 \_-3,5$ & $-7,1_{-}-4,7$ \\
\hline Regular & $-0,5 \_1,8$ & $-1,0 \_1,1$ & $-1,1 \_1,1$ & $-2,2-0,1$ & $-3,1 \_-0,8$ & $-3,4 \_-1,3$ & $-4,6-2,5$ \\
\hline Bom & $1,9 \_4,6$ & $1,2 \_3,9$ & $1,2 \_3,8$ & $0,0 \_2,8$ & $-0,7 \_2,2$ & $-1,2 \_1,1$ & $-2,4 \_0,0$ \\
\hline Muito bom & $\geq 4,7$ & $\geq 4,0$ & $\geq 3,9$ & $\geq 2,9$ & $\geq 2,3$ & $\geq 1,2$ & $\geq 0,1$ \\
\hline
\end{tabular}

Nota Fonte: Rikli, E. y Jones, J. (2001). Senior Fitness Test Manual. Champaign, IL: Human Kinetics. 
Tabela 8. Classificação do teste sentado e alcançar em mulheres

\begin{tabular}{lccccccc}
$\begin{array}{l}\text { Classificação: } \\
\text { (mulheres) }\end{array}$ & $\begin{array}{c}\mathbf{6 0 - 6 4} \\
\text { anos de } \\
\text { idade }\end{array}$ & $\begin{array}{c}\mathbf{6 5 - 6 9} \\
\text { anos de } \\
\text { idade }\end{array}$ & $\begin{array}{c}\mathbf{7 0 - 7 4} \\
\text { anos de } \\
\text { idade }\end{array}$ & $\begin{array}{c}\mathbf{7 5 - 7 9} \\
\text { anos de } \\
\text { idade }\end{array}$ & $\begin{array}{c}\mathbf{8 0 - 8 4} \\
\text { anos de } \\
\text { idade }\end{array}$ & $\begin{array}{c}\mathbf{8 5 - 8 9} \\
\text { anos de } \\
\text { idade }\end{array}$ & $\begin{array}{c}\mathbf{9 0 - 9 4} \\
\text { anos de } \\
\text { idade }\end{array}$ \\
\hline Muito fraco & $\leq-1,3$ & $\leq-1,0$ & $\leq-1,7$ & $\leq-2,0$ & $\leq-2,6$ & $\leq-3,2$ & $\leq-5,1$ \\
\hline Fraco & $-1,2 \_1,1$ & $-0,9 \_1,1$ & $-1,6 \_0,5$ & $-1,9 \_0,2$ & $-2,5 \_-0,4$ & $-3,1-1,0$ & $-5,0 \_-2,7$ \\
\hline Regular & $1,2 \_3,1$ & $1,2 \_2,9$ & $0,6 \_2,3$ & $0,3 \_2,1$ & $-0,3 \_1,4$ & $-0,9 \_0,8$ & $-2,6 \_-0,7$ \\
\hline Bom & $3,2-5,5$ & $3,0 \_5,0$ & $2,4 \_4,5$ & $2,2 \_4,4$ & $1,5 \_3,6$ & $0,9 \_3,0$ & $-0,6 \_1,7$ \\
\hline Muito bom & $\geq 5,6$ & $\geq 5,1$ & $\geq 4,6$ & $\geq 4,5$ & $\geq 3,7$ & $\geq 3,1$ & $\geq 1,8$ \\
\hline
\end{tabular}

Nota Fonte: Rikli, E. y Jones, J. (2001). Senior Fitness Test Manual. Champaign, IL: Human Kinetics.

\subsubsection{Sentado, caminhar $2,44 m$ e voltar a sentar}

\subsubsection{Objetivo}

O teste "sentado, caminhar $2,44 \mathrm{~m}$ e voltar a sentar" tem com finalidade avaliar a velocidade, a agilidade e o equilíbrio dinâmico.

\subsubsection{Equipamento necessário:}

Um cronómetro, uma fita métrica, um cone ou marcador e uma cadeira com encosto (sem braços), com altura do assento de aproximadamente 43 centímetros.

\subsubsection{Descrição}

A cadeira deve ser posicionada contra uma parede ou de outra forma a garantir que a mesma fique numa posição estática durante o teste. A cadeira deve estar numa zona desobstruída, em frente a um cone à distância de 2,44m (esta medida deve ser realizada desde a ponta da cadeira até à parte anterior do cone ou marcador). À volta do cone ou marcador deve existir um espaço livre de pelo menos $1,22 \mathrm{~m}$ de forma a permitir que o participante contornar o mesmo livremente.

O participante inicia o teste na posição sentado na cadeira, numa postura ereta, mãos nas coxas e com os pés totalmente assentes no solo, um ligeiramente avançado em relação ao outro. Ao sinal de "partida" o participante eleva-se da cadeira, caminha o mais rápido possível, contorna o cone ou marcador (por qualquer dos lados) e regressa à posição inicial. $O$ avaliador deve informar o participante de que se trata de um teste "por tempo" sendo o objetivo do mesmo caminhar o mais rápido possível, sem correr, contornar o cone ou marcador e voltar à posição inicial. O avaliador deve dar assistência ao participante, mantendo-se por perto, de forma a dar assistência em caso de o participante se desequilibrar. O cronómetro deve ser iniciado ao sinal de "partida" (quer o participante tenha ou não iniciado o movimento) e deve ser parado no momento exato em que o participante se senta novamente na cadeira. O participante deve realizar um ou dois ensaios após a demonstração por parte do avaliador. 


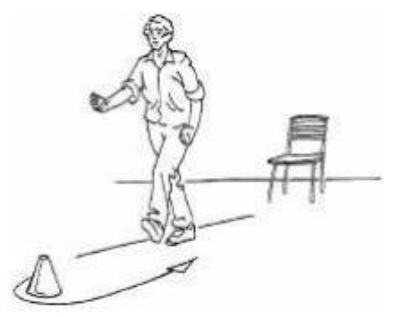

Figura 4 - Teste sentado, caminhar 2,44 metros e voltar a sentar (Rikli y Jones, 2001).

\subsubsection{Avaliação e classificação}

A avaliação é obtida através do tempo decorrido entre o sinal de "partida" até ao momento em que o participante se senta novamente na cadeira. Devem ser registados dois valores até ao 0,01 ', sendo o melhor resultado utilizado para medir o desempenho do participante. Quanto à classificação, a mesma é obtida tendo em conta as tabelas 9 e 10.

Tabela 1. Classificação do teste sentado, caminhar 2,44 metros e voltar a sentar em homens

\begin{tabular}{|c|c|c|c|c|c|c|c|}
\hline $\begin{array}{l}\text { Classificação: } \\
\text { (homens) }\end{array}$ & $\begin{array}{c}\text { 60-64 } \\
\text { anos de } \\
\text { idade }\end{array}$ & $\begin{array}{c}65-69 \\
\text { anos de } \\
\text { idade }\end{array}$ & $\begin{array}{c}70-74 \\
\text { anos de } \\
\text { idade }\end{array}$ & $\begin{array}{c}75-79 \\
\text { anos de } \\
\text { idade }\end{array}$ & $\begin{array}{c}80-84 \\
\text { anos de } \\
\text { idade }\end{array}$ & $\begin{array}{c}85-89 \\
\text { anos de } \\
\text { idade }\end{array}$ & $\begin{array}{c}90-94 \\
\text { anos de } \\
\text { idade }\end{array}$ \\
\hline Muito fraco & $\geq 5,8$ & $\geq 6,1$ & $\geq 6,4$ & $\geq 7,5$ & $\geq 7,9$ & $\geq 9,4$ & $\geq 10,5$ \\
\hline Fraco & $5,7-5,0$ & $6,0-5,4$ & $6,3-5,6$ & $7,4-6,4$ & $7,8-6,9$ & $9,3-7,9$ & $10,4-8,8$ \\
\hline Regular & $4,9-4,4$ & $5,3-4,8$ & $5,5-5,0$ & $6,3-5,4$ & $6,8-6,0$ & $7,8-6,5$ & $8,7-7,4$ \\
\hline Bom & $4,3-3,6$ & $4,7-4,1$ & $4,9-4,2$ & $5,3-4,3$ & $5,9-4,9$ & $6,4-5,0$ & $7,3-5,7$ \\
\hline Muito bom & $\leq 3,5$ & $\leq 4,0$ & $\leq 4,1$ & $\leq 4,2$ & $\leq 4,8$ & $\leq 4,9$ & $\leq 5,6$ \\
\hline
\end{tabular}

Nota Fonte: Rikli, E. y Jones, J. (2001). Senior Fitness Test Manual. Champaign, IL: Human Kinetics.

Tabela 2. Classificação do teste sentado, caminhar 2,44 metros e voltar a sentar em mulheres

\begin{tabular}{lccccccc}
\hline $\begin{array}{l}\text { Classificação: } \\
\text { (mulheres) }\end{array}$ & $\begin{array}{c}\mathbf{6 0 - 6 4} \\
\text { anos de } \\
\text { idade }\end{array}$ & $\begin{array}{c}\mathbf{6 5 - 6 9} \\
\text { anos de } \\
\text { idade }\end{array}$ & $\begin{array}{c}\mathbf{7 0 - 7 4} \\
\text { anos de } \\
\text { idade }\end{array}$ & $\begin{array}{c}\mathbf{7 5 - 7 9} \\
\text { anos de } \\
\text { idade }\end{array}$ & $\begin{array}{c}\mathbf{8 0 - 8 4} \\
\text { anos de } \\
\text { idade }\end{array}$ & $\begin{array}{c}\mathbf{8 5 - 8 9} \\
\text { anos de } \\
\text { idade }\end{array}$ & $\begin{array}{c}\mathbf{9 0 - 9 4} \\
\text { anos de } \\
\text { idade }\end{array}$ \\
\hline Muito fraco & $\geq 6,2$ & $\geq 6,6$ & $\geq 7,3$ & $\geq 7,6$ & $\geq 9,0$ & $\geq 10,0$ & $\geq 12,1$ \\
\hline Fraco & $6,1-5,5$ & $6,5-5,9$ & $7,2-6,4$ & $7,5-6,7$ & $8,9-7,8$ & $9,9-8,5$ & $12,0-10,2$ \\
\hline Regular & $5,4-4,9$ & $5,8-5,3$ & $6,3-5,6$ & $6,6-5,9$ & $7,7-6,7$ & $8,4-7,3$ & $10,1-8,6$ \\
\hline Bom & $4,8-4,2$ & $5,2-4,6$ & $5,5-4,7$ & $5,8-5,0$ & $6,6-5,4$ & $7,2-5,8$ & $8,5-6,7$ \\
\hline Muito bom & $\leq 4,1$ & $\leq 4,5$ & $\leq 4,6$ & $\leq 4,9$ & $\leq 5,3$ & $\leq 5,7$ & $\leq 6,6$ \\
\hline
\end{tabular}

Nota Fonte: Rikli, E. y Jones, J. (2001). Senior Fitness Test Manual. Champaign, IL: Human Kinetics. 


\subsubsection{Alcançar atrás das costas}

\subsubsection{Objetivo}

O teste "alcançar atrás das costas" tem como objetivo avaliar a flexibilidade dos membros superiores.

\subsubsection{Equipamento necessário}

Uma régua de 45 centímetros.

\subsubsection{Descrição}

O teste inicia-se com o participante na posição de pé. O mesmo coloca a mão dominante por cima dele próprio e alcança o mais abaixo que conseguir em direção ao meio das costas com a palma da mão virada para baixo e os dedos esticados, o cotovelo deve apontar para cima. A outra mão é colocada por debaixo das costas e por atrás, com a palma da mão virada para cima, tentado alcançar o mais longe possível com o objetivo de tocar ou sobrepor os dedos médios de ambas as mãos. Após um ou dois ensaios o participante inicia o teste.

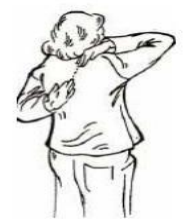

Figura 5 - Teste alcançar atrás das costas (Rikli y Jones, 2001).

\subsubsection{Avaliação e classificação}

A avaliação é atribuída através da distância de sobreposição ou a distância entre os dedos médios. Os resultados negativos representam a distância mais curta entre os dois dedos médios e os resultados positivos representam a medida de sobreposição dos dedos médios. Devem ser registadas duas medidas, sendo o melhor resultado utilizado para medir o desempenho. O avaliador deve garantir que são registados os sinais de $-\mathrm{e}+$ na ficha de registos. A classificação é realizada tendo em conta as tabelas 11 e 12 .

Tabela 11. Classificação do teste alcançar atrás das costas em homens

\begin{tabular}{lccccccc}
$\begin{array}{l}\text { Classificação: } \\
\text { (homens) }\end{array}$ & $\begin{array}{c}\mathbf{6 0 - 6 4} \\
\text { anos de } \\
\text { idade }\end{array}$ & $\begin{array}{c}\mathbf{6 5 - 6 9} \\
\text { anos de } \\
\text { idade }\end{array}$ & $\begin{array}{c}\mathbf{7 0 - 7 4} \\
\text { anos de } \\
\text { idade }\end{array}$ & $\begin{array}{c}\mathbf{7 5 - 7 9} \\
\text { anos de } \\
\text { idade }\end{array}$ & $\begin{array}{c}\mathbf{8 0 - 8 4} \\
\text { anos de } \\
\text { idade }\end{array}$ & $\begin{array}{c}\mathbf{8 5 - 8 9} \\
\text { anos de } \\
\text { idade }\end{array}$ & $\begin{array}{c}\mathbf{9 0 - 9 4} \\
\text { anos de } \\
\text { idade }\end{array}$ \\
\hline Muito fraco & $\leq-7,4$ & $\leq-8,2$ & $\leq-8,6$ & $\leq-9,9$ & $\leq-10,5$ & $\leq-10,2$ & $\leq-11,2$ \\
\hline Fraco & $-7,3-4,6$ & $-8,1-5,3$ & $-8,5-5,7$ & $-9,8_{-}-6,9$ & $-10,4--7,1$ & $-10,0_{-}-7,4$ & $-11,1_{-}-8,4$ \\
\hline Regular & $-4,5_{-}-2,2$ & $-5,2_{-}-2,9$ & $-5,6_{-}-3,3$ & $-6,8_{-}-4,3$ & $-7,0_{-}-4,3$ & $-7,3_{-}-5,0$ & $-8,3_{-}-6,0$ \\
\hline Bom & $-2,1 \_0,6$ & $-2,8_{-} 0$ & $-3,2_{-}-0,4$ & $-4,2-1,3$ & $-4,2_{-}-1,2$ & $-4,9_{-}-2,2$ & $-5,9+-3,2$ \\
\hline Muito bom & $\geq 0,7$ & $\geq 0,1$ & $\geq-0,3$ & $\geq-1,2$ & $\geq-1,1$ & $\geq-2,1$ & $\geq-3,1$ \\
\hline
\end{tabular}

Nota Fonte: Rikli, E. y Jones, J. (2001). Senior Fitness Test Manual. Champaign, IL: Human Kinetics. 
Tabela 12. Classificação do teste alcançar atrás das costas em mulheres

\begin{tabular}{|c|c|c|c|c|c|c|c|}
\hline $\begin{array}{l}\text { Classificação: } \\
\text { (mulheres) }\end{array}$ & $\begin{array}{c}60-64 \\
\text { anos de } \\
\text { idade }\end{array}$ & $\begin{array}{c}65-69 \\
\text { anos de } \\
\text { idade }\end{array}$ & $\begin{array}{c}70-74 \\
\text { anos de } \\
\text { idade }\end{array}$ & $\begin{array}{c}75-79 \\
\text { anos de } \\
\text { idade }\end{array}$ & $\begin{array}{c}80-84 \\
\text { anos de } \\
\text { idade }\end{array}$ & $\begin{array}{c}85-89 \\
\text { anos de } \\
\text { idade }\end{array}$ & $\begin{array}{c}90-94 \\
\text { anos de } \\
\text { idade }\end{array}$ \\
\hline Muito fraco & $\leq-3,6$ & $\leq-4,3$ & $\leq-4,9$ & $\leq-5,5$ & $\leq-6,1$ & $\leq-7,7$ & $\leq-8,9$ \\
\hline Fraco & $-3,5--1,6$ & $-4,2 \_-2,1$ & $-4,8--2,6$ & $-5,4 \_-3,1$ & $-6,0 \_-3,7$ & $-7,6 \_-5,0$ & $-8,8 \_-5,8$ \\
\hline Regular & $-1,5 \_0,2$ & $-2,0 \_-0,3$ & $-2,5 \_-0,8$ & $-3,0 \_-1,1$ & $-3,6 \_-1,6$ & $-4,9-2,8$ & $-5,7 \_-3,2$ \\
\hline Bom & $0,3 \_1,9$ & $-0,2 \_1,9$ & $-0,7 \_1,5$ & $-1,0 \_1,3$ & $-1,5 \_0,9$ & $-2,7 \_-0,1$ & $-3,1 \_-0,1$ \\
\hline Muito bom & $\geq 2,0$ & $\geq 2,0$ & $\geq 1,6$ & $\geq 1,4$ & $\geq 1,1$ & $\geq 0,0$ & $\geq 0,0$ \\
\hline
\end{tabular}

Nota Fonte: Rikli, E. y Jones, J. (2001). Senior Fitness Test Manual. Champaign, IL: Human Kinetics.

\subsubsection{Andar 6 minutos}

\subsubsection{Objetivo}

O teste "andar durante 6 minutos" tem como objetivo avaliar a avaliar a resistência aeróbica.

\subsubsection{Equipamento necessário}

Um cronómetro, uma fita métrica, paus ou pedrinhas, cones, giz, um marcador. Por razões de segurança, foram colocadas cadeiras ao longo de vários pontos.

\subsubsection{Montagem}

O teste envolveu a medição da distância máxima de deslocamento, durante 6 minutos, ao longo de um percurso de 50 metros, com marcações de 5 em 5 metros. $O$ perímetro interno da distância medida, foi delimitada com cones e os segmentos de 5 metros com marcador ou giz. A área de percurso era bem iluminada, a superfície era lisa e não deslizante.

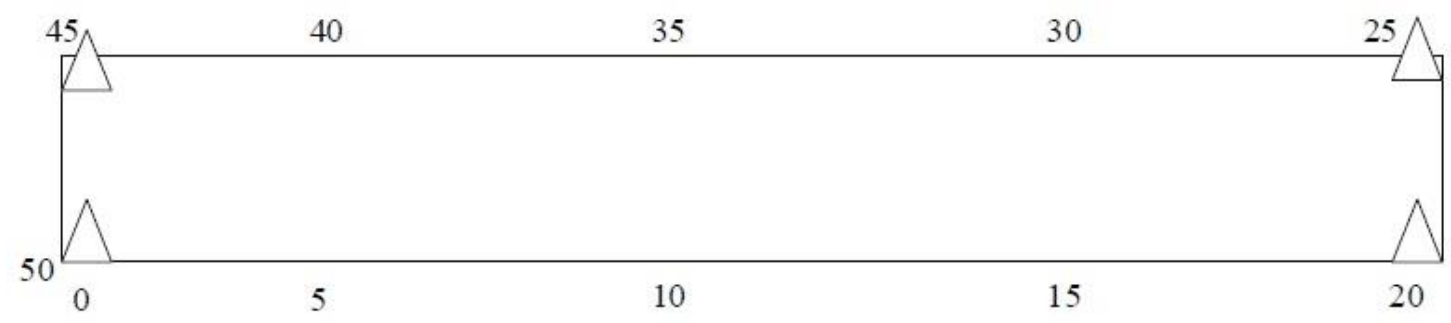

Figura 6 - Teste andar durante 6 minutos (Rikli y Jones, 2001).

\subsubsection{Descrição}

De forma a facilitar o processo de contabilização das voltas do percurso, utilizámos dois processos em que cada participante que tinha a função de contar o número de voltas escolhia o preferencial, um deles foi uma folha de registo, o outro foi através de paus/pedrinhas. Ao sinal de "partida", os participantes foram instruídos para caminharem o mais rápido possível, sem correrem, na distância marcada à volta dos cones. Durante o teste os participantes podiam parar e descansar, se necessário, e 
depois voltar a caminhar. O avaliador moveu-se para dentro do percurso após todos os participantes terem começado. Os tempos intermédios foram anunciados aproximadamente a meio do percurso, quando faltavam 2 minutos e quando faltava 1 minuto. No final dos 6 minutos, os participantes foram instruídos a parar, deslocandose para a direita, onde um assistente registou a distância percorrida.

\subsubsection{Avaliação e classificação}

O avaliador registou a distância percorrida (metros) no intervalo de 6 minutos. A classificação é realizada tendo em conta as tabelas 13 e 14.

Tabela 13. Classificação do teste andar durante 6 minutos - distância em metros em homens

\begin{tabular}{lcccccccc} 
Classificação: & $\begin{array}{c}\mathbf{6 0 - 6 4} \\
\text { anos de } \\
\text { (homens) }\end{array}$ & $\begin{array}{c}\mathbf{6 5 - 6 9} \\
\text { anos de } \\
\text { idade }\end{array}$ & $\begin{array}{c}\mathbf{7 0 - 7 4} \\
\text { anos de } \\
\text { idade }\end{array}$ & $\begin{array}{c}\mathbf{7 5 - 7 9} \\
\text { anos de } \\
\text { idade }\end{array}$ & $\begin{array}{c}\mathbf{8 0 - 8 4} \\
\text { anos de } \\
\text { idade }\end{array}$ & $\begin{array}{c}\mathbf{8 5 - 8 9} \\
\text { anos de } \\
\text { idade }\end{array}$ & $\begin{array}{c}\text { 90-94 } \\
\text { anos de } \\
\text { idade }\end{array}$ \\
\hline Muito fraco & $\leq 597$ & $\leq 544$ & $\leq 526$ & $\leq 449$ & $\leq 423$ & $\leq 358$ & $\leq 279$ \\
\hline Fraco & $598-651$ & $545-605$ & $527-586$ & $450-524$ & $424-494$ & $359-442$ & $280-366$ \\
\hline Regular & $652-697$ & $606-657$ & $587-638$ & $525-586$ & $495-554$ & $443-512$ & $367-440$ \\
\hline Bom & $698-751$ & $658-718$ & $639-698$ & $587-661$ & $555-625$ & $513-596$ & $441-527$ \\
\hline Muito bom & $\geq 752$ & $\geq 719$ & $\geq 699$ & $\geq 662$ & $\geq 626$ & $\geq 597$ & $\geq 528$ \\
\hline
\end{tabular}

Nota Fonte: Rikli, E. y Jones, J. (2001). Senior Fitness Test Manual. Champaign, IL: Human Kinetics.

Tabela 14. Classificação do teste andar durante 6 minutos - distância em metros em mulheres

\begin{tabular}{lccccccc}
\hline $\begin{array}{l}\text { Classificação: } \\
\text { (mulheres) }\end{array}$ & $\begin{array}{c}\mathbf{6 0 - 6 4} \\
\text { anos de } \\
\text { idade }\end{array}$ & $\begin{array}{c}\mathbf{6 5 - 6 9} \\
\text { anos de } \\
\text { idade }\end{array}$ & $\begin{array}{c}\mathbf{7 0 - 7 4} \\
\text { anos de } \\
\text { idade }\end{array}$ & $\begin{array}{c}\mathbf{7 5 - 7 9} \\
\text { anos de } \\
\text { idade }\end{array}$ & $\begin{array}{c}\mathbf{8 0 - 8 4} \\
\text { anos de } \\
\text { idade }\end{array}$ & $\begin{array}{c}\mathbf{8 5 - 8 9} \\
\text { anos de } \\
\text { idade }\end{array}$ & $\begin{array}{c}\mathbf{9 0 - 9 4} \\
\text { anos de } \\
\text { idade }\end{array}$ \\
\hline Muito fraco & $\leq 532$ & $\leq 483$ & $\leq 466$ & $\leq 413$ & $\leq 364$ & $\leq 318$ & $\leq 251$ \\
\hline Fraco & $533-582$ & $484-543$ & $467-524$ & $414-480$ & $365-433$ & $319-394$ & $252-326$ \\
\hline Regular & $583-624$ & $544-593$ & $525-572$ & $481-538$ & $434-491$ & $395-458$ & $327-388$ \\
\hline Bom & $625-674$ & $594-653$ & $573-630$ & $539-605$ & $492-560$ & $459-534$ & $389-463$ \\
\hline Muito bom & $\geq 675$ & $\geq 654$ & $\geq 631$ & $\geq 606$ & $\geq 561$ & $\geq 535$ & $\geq 464$ \\
\hline
\end{tabular}

Nota Fonte: Rikli, E. y Jones, J. (2001). Senior Fitness Test Manual. Champaign, IL: Human Kinetics.

\subsection{Recolha de dados}

A recolha de dados foi realizada num único momento a individuos voluntários, na tabela 15, segue o cronograma elaborado para a recolha respetiva.

Tabela 15. Cronograma de recolha de dados

\section{Praticantes de AFO}

Freguesias de Pampilhosa da Serra

Outubro de 2015

Apresentação do estudo

Autorização de participação investigação

Avaliação da aptidão física

\section{Não praticantes de AFO}

Associação de Solidariedade Social de Dornelas do Zêzere Julho de 2016 Apresentação do estudo

na Autorização de participação na investigação Avaliação da aptidão física 


\subsection{Procedimento de recolha de dados}

Após ser realizada a recolha de dados, torna-se fulcral o tratamento de análise dos mesmos, usamos para tal o programa de estatística S.P.S.S. (Statistical Package for the Social Sciences), versão 23.0. De acordo com os procedimentos apresentados posteriormente foi efetuada uma análise prévia dos dados para identificar outliers (valores não aceitáveis) e para verificar se todos os dados correspondiam a participantes que cumprem os requisitos que foram definidos para a investigação.

A análise descritiva dos dados foi efetuada a partir das medidas descritivas básicas, média e desvio padrão. Foi utilizado o teste não paramétrico de KolmogorovSmirnov para testar a normalidade das variáveis em cada um dos grupos de estudo, sempre que o $n>30$, quando o $n<30$, foi utilizado o teste Shapiro-Wilk para testar a normalidade, este foi realizado na análise entre freguesias.

Nas variáveis que têm a distribuição normal, foi aplicado o teste $\mathrm{t}$ - student para medidas independentes e, quando as variáveis apresentaram mais do que duas categorias, foi utilizada a "análise de variância" (Anova), com comparações múltiplas de Scheffé, considerando o nível de significância de 0,05. Nas variáveis que não têm distribuição normal, foi aplicado o teste não paramétrico U-Mann-Whitney para medidas independentes, e quando as variáveis apresentaram mais do que duas categorias foi utilizado o teste não paramétrico de Kruskal-Wallis Test, considerando o nível de significância de 0,05, ou seja, com um nível de confiança de 95\%.

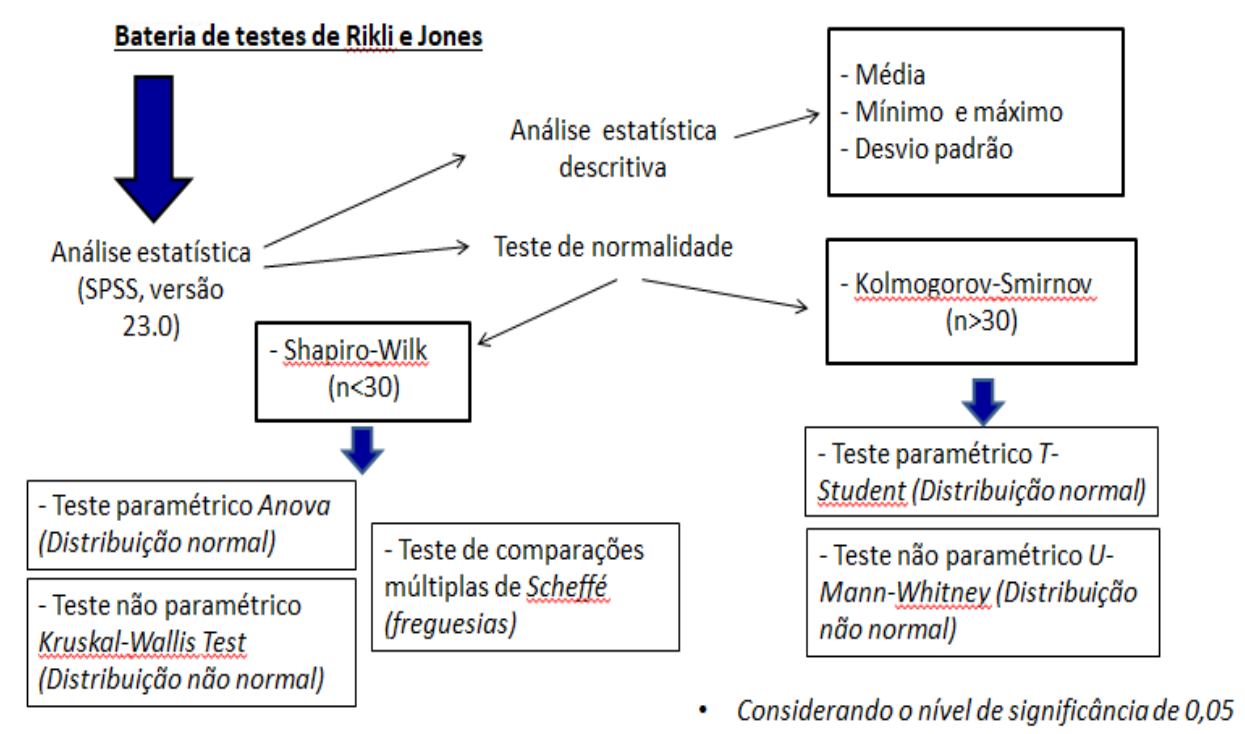

Figura 7 - Análise Estatística

\section{RESULTADOS}

\subsection{Estatística Descritiva (Geral)}

Começamos por apresentar uma descrição geral dos indivíduos relativamente a alguns aspetos morfológicos, como a idade, altura, peso e índice de massa corporal (IMC). 
Tabela 16. Parámetros Morfológicos

\begin{tabular}{|l|c|c|}
\hline & Praticantes & Nä́ Praticantes \\
\hline Idade & 71 & 82 \\
\hline Altura & 157 & 156 \\
\hline Peso & 71,5 & 66,2 \\
\hline IMC & 28,7 & 27,2 \\
\hline
\end{tabular}

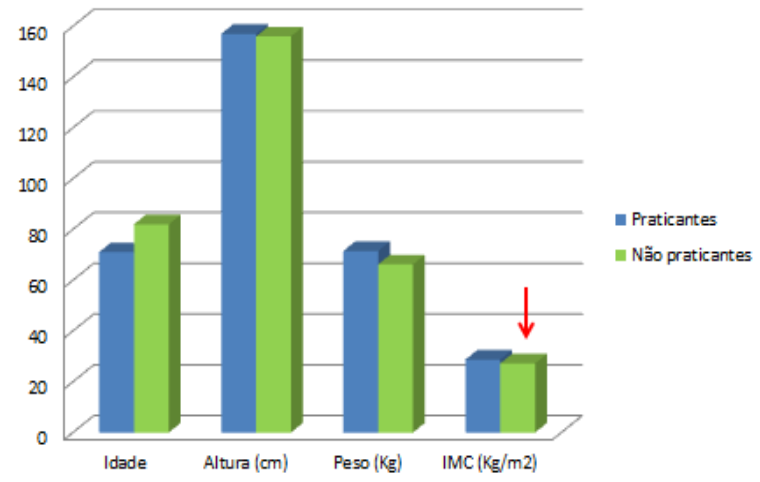

Relativamente à aptidão física começamos por apresentar uma análise geral dos dados. Como podemos observar na tabela 17 para o teste levantar e sentar na cadeira, os praticantes apresentaram uma média de 16 repetições, superior à média apresentada pelos não praticantes que registaram 7 repetições. No teste flexão do antebraço, os praticantes atingiram uma média de 21 repetições e os não praticantes obtiveram um valor médio de 9 repetições. No teste sentado e alcançar a média nos praticantes foi positiva com um valor médio de $+6 \mathrm{~cm}$ e já os não praticantes foi negativa, com um valor médio de $-9 \mathrm{~cm}$. No teste sentado, caminhar $2,44 \mathrm{~m}$ e voltar a sentar, os praticantes alcançaram uma média de 6 segundos, já os não praticantes atingiram uma média de 21 segundos. No teste, alcançar atrás das costas, apesar da média dos dois grupos ter sido negativa, os praticantes atingiram uma média de $10 \mathrm{~cm}$, já os não praticantes alcançaram uma média de $-30 \mathrm{~cm}$. Relativamente ao teste andar durante 6 minutos os praticantes percorreram em média 571 metros, já os não praticantes alcançaram um valor médio de 125 metros. Tendo em conta os resultados apresentados, podemos referir que relativamente às médias os praticantes alcançaram melhores resultados em todos os testes aplicados.

Tabela 17. Aptidão Física

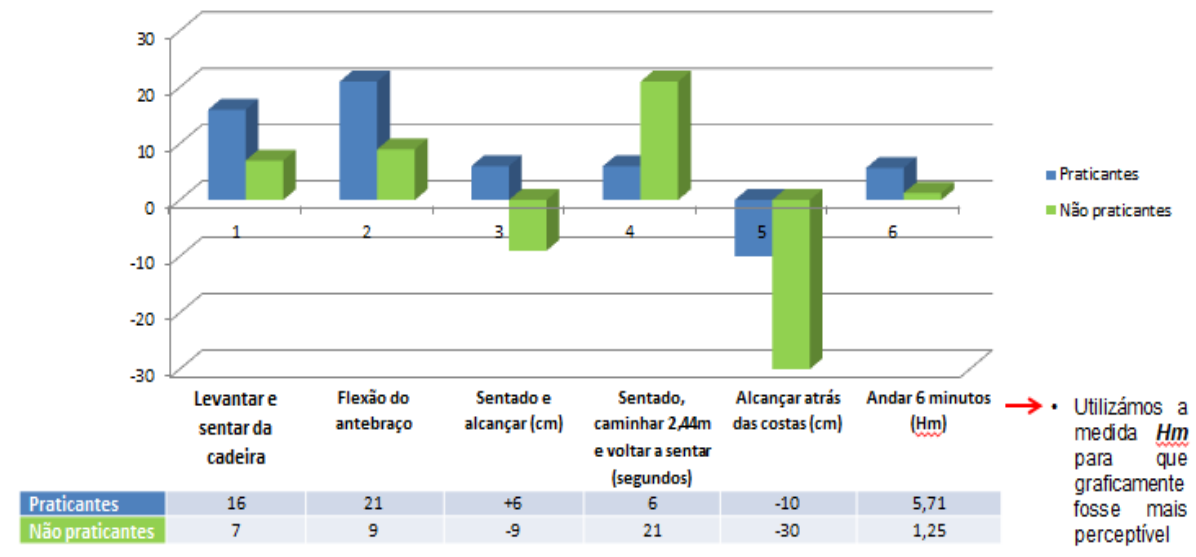




\subsection{Testes Estatísticos}

Para verificar a normalidade na distribuição dos dados da amostra aplicámos o teste de Kolmogorov-Smirnov $(n>30)$, como podemos observar na tabela 18.

Tabela 18. Teste da Normalidade (Kolmogorov-Smirnov $-n>30$ )

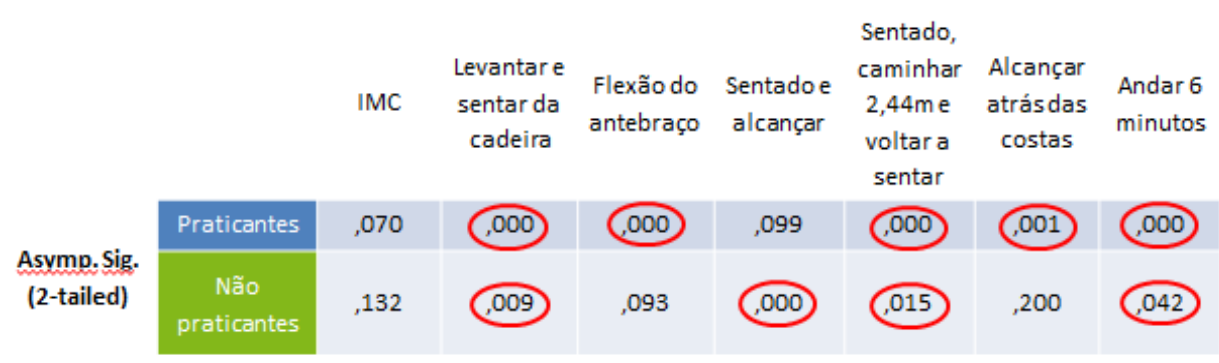

Como podemos constatar na tabela anterior, o IMC em ambos os grupos apresenta uma distribuição normal (Sig. > 0,05), nos restantes testes existiu pelo menos um grupo cuja distribuição era não normal (Sig. < 0,05).

\section{Diferenças estatisticamente significativas (Distribuição Normal)}

Tabela 19. Teste paramétrico T-Student

\section{Diferenças estatisticamente significativas (Distribuição Não Normal)}

Tabela 20. Teste não paramétrico U-Mann-Whitney
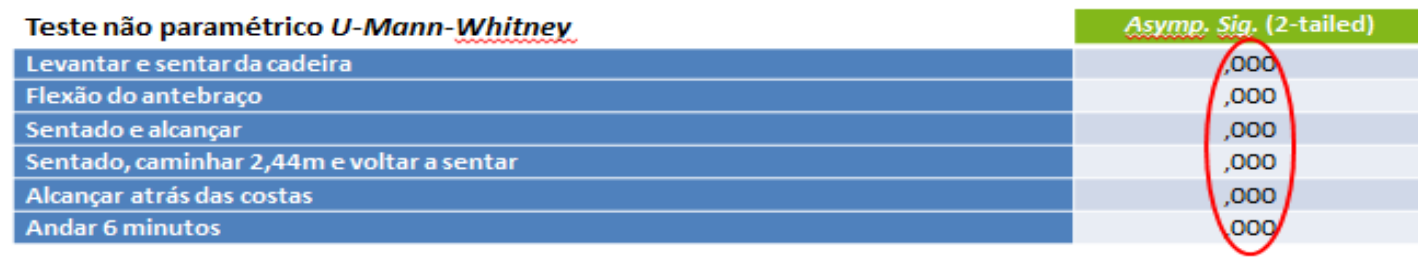

Através dos valores representados nas tabelas podemos constatar que existem diferenças estatisticamente significativas em todos os parâmetros avaliados, visto que o Sig. $<0,05$.

De acordo com Paulo (2010) e com o nosso estudo ambos constatámos que são evidenciados melhores resultados em todos os testes de ApF de praticantes de AFO em relação aos não praticantes de AFO/sedentários.

\subsection{Estatística Descritiva (Freguesias)}

De seguida analisamos os dados tendo em conta a freguesia a que os utentes praticantes de atividade física organizada pertencem. Nesta parte do estudo, a amostra foi dividida em 8 grupos e procedeu-se à análise estatística com a finalidade de verificar se havia ou não diferenças estatisticamente significativas entre os diversos grupos. 
Tabela 21. Parámetros Morfológicos

\begin{tabular}{|l|c|c|}
\hline Freguesia & N & IMC \\
\hline Cabril & 20 & 29,4 \\
\hline Dornelas do Zêzere & 20 & 28,4 \\
\hline Fajäo - Vidual & 22 & 28,2 \\
\hline Janeiro de Baixo & 23 & 29,4 \\
\hline Portela do Fojo - Machio & 29 & 30,2 \\
\hline Pampilhosa da Serra & 8 & 27,3 \\
\hline Pessegueiro & 28 & 27,5 \\
\hline Unhais-o-Velho & 6 & 26,8 \\
\hline
\end{tabular}

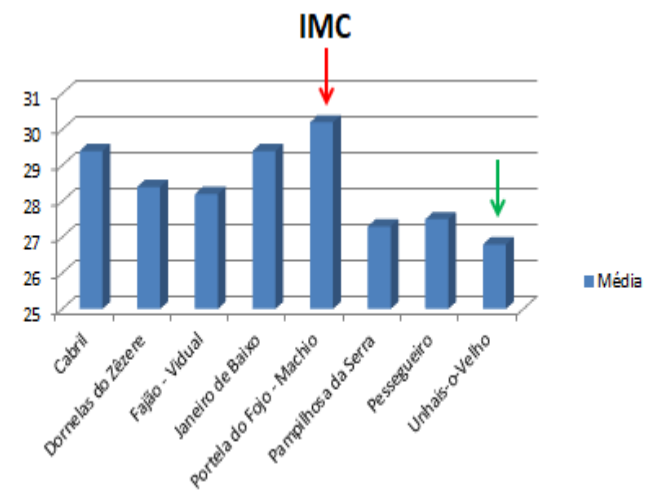

Como podemos observar na tabela 21 a média mais elevada de IMC é na freguesia de Portela do Fojo - Machio com um valor de $30,2 \mathrm{Kg} / \mathrm{m} 2$ e o valor médio mais baixo de IMC é na freguesia de Unhais-o-Velho com o valor de $26,8 \mathrm{Kg} / \mathrm{m} 2$. Numa primeira análise podemos referir que a freguesia de Unhais-o-Velho é aquela que apresenta um IMC mais próximo do intervalo saudável, segundo a classificação do Índice de Massa Corporal de Rikli y Jones (2001).

Relativamente à aptidão física começamos por apresentar os valores alcançados por cada freguesia em relação aos testes de aptidão física funcional e posteriormente analisamos se existem diferenças estatisticamente significativas entre as mesmas.

Tabela 22. Aptidão Física

\begin{tabular}{|l|c|c|c|c|c|c|}
\hline Freguesia & $\begin{array}{c}\text { Levantare } \\
\text { sentar da } \\
\text { cadeira }\end{array}$ & $\begin{array}{c}\text { Flexäo do } \\
\text { Antebrạ̧o }\end{array}$ & $\begin{array}{c}\text { Sentado, } \\
\text { Sentadoe }\end{array}$ & $\begin{array}{c}\text { Alcanģar (cm) } \\
\text { caminhar 2,44m } \\
\text { evoltara sentar } \\
\text { (segundos) }\end{array}$ & $\begin{array}{c}\text { Alcançar atrás } \\
\text { das costas (cm) }\end{array}$ & $\begin{array}{c}\text { Andar 6 } \\
\text { minutos } \\
\text { (metros) }\end{array}$ \\
\hline Cabril & 13 & 18 & +3 & 7 & -15 & 348 \\
\hline Dornelas do Zêzere & 17 & 31 & +11 & 5 & -7 & 849 \\
\hline Fajäo- Vidual & 19 & 26 & +7 & 7 & -8 & 563 \\
\hline Janeiro de Baixo & 14 & 16 & +7 & 5 & -9 & 521 \\
\hline Portela do Fojo- Machio & 15 & 16 & +5 & 7 & -8 & 534 \\
\hline Pampilhosa da Serra & 19 & 18 & +14 & 5 & -14 & 544 \\
\hline Pessegueiro & 16 & 23 & 0 & 6 & -12 & 634 \\
\hline Unhais-o-Velho & 20 & 19 & +425 & -4 & -9 & 530 \\
\hline
\end{tabular}

Como podemos observar na tabela 22 para o teste levantar e sentar na cadeira, a freguesia que apresentou melhor média de resultados foi a de Unhais-oVelho com 20 repetições. No teste flexão do antebraço, a freguesia que apresentou uma média mais significativa foi a de Dornelas do Zêzere com 31 repetições. No teste sentado e alcançar a média mais alta foi a de Unhais-o-Velho com $+25 \mathrm{~cm}$. No teste sentado, caminhar $2,44 \mathrm{~m}$ e voltar a sentar, a freguesia que alcançou melhor média foi a de Unhais-o-Velho com 4,37 segundos. No teste, alcançar atrás das costas, apesar da média de todas as freguesias ter sido negativa, a freguesia que apresentou melhor média foi a de Dornelas do Zêzere com $-6,85 \mathrm{~cm}$. Relativamente ao teste andar durante 6 minutos podemos observar que a freguesia de Dornelas do Zêzere foi aquela que apresentou uma melhor média com 845 metros. Tendo em conta os resultados apresentados, podemos referir que relativamente às médias, as freguesias de Unhais-o-Velho e Dornelas do Zêzere foram no geral as que alcançaram melhores resultados. 


\subsection{Testes Estatísticos}

Para verificar a normalidade na distribuição dos dados em cada um dos grupos foi aplicado o teste de Shapiro-Wilk $(n<30)$, como podemos observar na tabela 23.

Tabela 23. Teste da normalidade (Shapiro-Wilk $-\mathrm{n}<30$ )

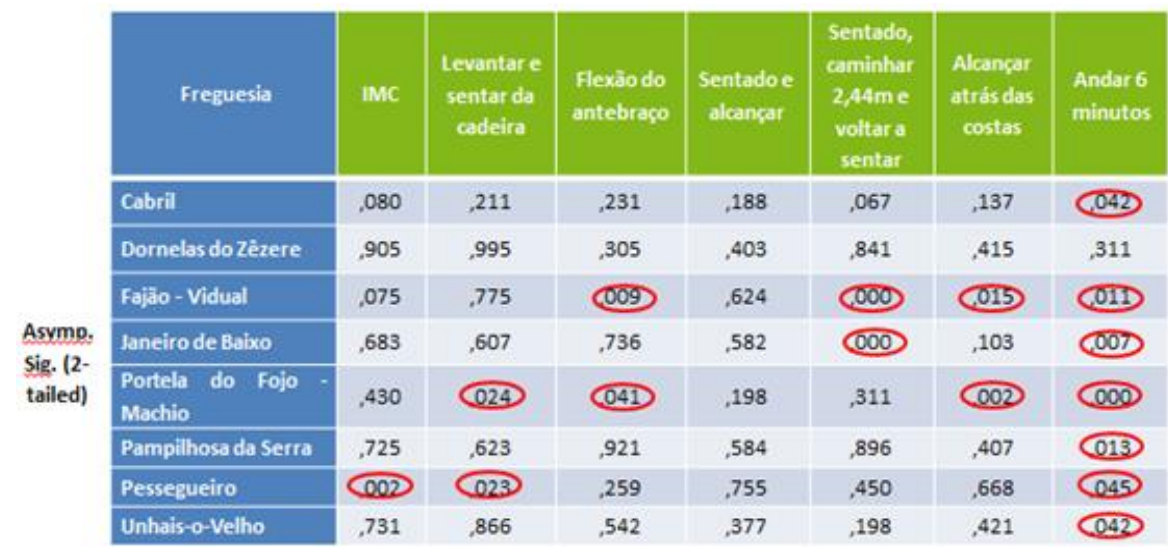

Para verificarmos se existiam ou não diferenças estatisticamente significativas entre as freguesias foram aplicados:

- Para os casos em que a distribuição se verificou ser normal (Sig. > 0,05), utilizámos o teste paramétrico Anova. Como podemos constatar na tabela 24, para 0 teste sentado e alcançar obtivemos um valor de Sig. > 0,05 em todas as freguesias.

- Para os casos em que a distribuição se verificou ser não normal (Sig. $<0,05)$ utilizámos o teste não paramétrico Kruskal-Wallis Test como referido na tabela 25 . Em todos os outros testes obtivemos uma distribuição não normal, um valor de Sig. $<0,05$, em pelo menos uma das freguesias.

\section{Diferenças estatisticamente significativas (Distribuição Normal)}

Tabela 24. Teste paramétrico A-nova

\section{Diferenças estatisticamente significativas (Distribuição Não Normal)}

Teste paramétrico $A$-nova

Sentado e alcançar

\section{Asymo. Siq. (2-tailed)}

(000)

Tabela 25. Teste não paramétrico Kruskal-Wallis Test

Teste não paramétrico Kruskal-Wallis Test

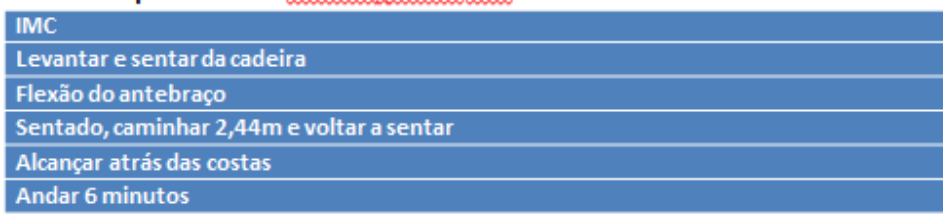

Através dos valores representados nas tabelas podemos constatar que existem diferenças estatisticamente significativas nos testes sentado e alcançar, levantar e sentar da cadeira, flexão do antebraço, sentado, caminhar $2,44 \mathrm{~m}$ e voltar a sentar e andar durante 6 minutos, visto que o Sig. $<0,05$ 
Para observarmos onde ocorrem as diferenças estatisticamente significativas entre as freguesias, foi aplicado o teste de comparações múltiplas de Scheffé referido na tabela 26.

Tabela 26. Teste de comparações múltiplas de Scheffé

\begin{tabular}{|c|c|c|c|}
\hline (1) Freguesia & (J) Freguesia & Diferença média (I-J) & $\begin{array}{c}\text { Asymu. Sig. (2 } \\
\text { tailed) }\end{array}$ \\
\hline \multirow{7}{*}{ Pessegueiro } & Cabril & $-3,164$ &, 971 \\
\hline & Dornelas do Zêzere & $-11,364^{*}$ & (003) \\
\hline & Fajão-Vidual & $-7,782$ &, 139 \\
\hline & Janeiro de Baixo & $-7,116$ & 220 \\
\hline & Portela do Fojo-Machio & $-5,016$ & ,613 \\
\hline & Pampilhosa da Serra & $-14,464^{*}$ & 009 \\
\hline & Unhais-o-Velho & $-25,464^{\circ}$ & 000 \\
\hline \multirow{7}{*}{ Unhais-o-Velho } & Cabril & $22,300^{\circ}$ & 000 \\
\hline & Dornelas do Zêzere & 14,100 &, 063 \\
\hline & Fajão-Vidual & $17,682^{\circ}$ & (004) \\
\hline & Janeiro de Baixo & $18,348^{\circ}$ & 002 \\
\hline & Portela do Fojo-Machio & $20,448^{\circ}$ & 000 \\
\hline & Pampilhosa da Serra & 11,000 &, 515 \\
\hline & Pessegueiro & $25,464^{\circ}$ & 000 \\
\hline
\end{tabular}

\section{DISCUSSÃO}

Resumindo, podemos constatar que a prática de atividade física organizada (Ginástica Sénior) teve um impacto positivo nos níveis de aptidão física dos idosos, tendo sido visíveis melhorias nas médias dos resultados em praticamente todos os testes aplicados, em comparação ao grupo de não praticantes de atividade física organizada. Quanto às diferenças estatisticamente significativas entre os grupos de praticantes e não praticantes de AFO foram visíveis em todos os testes de Aptidão Física Funcional (IMC; Levantar e sentar da cadeira; Flexão do antebraço; Sentado e alcançar; Sentado, caminhar 2,44m e voltar a sentar; Alcançar atrás das costas; Caminhar 6 minutos). Relativamente às diferenças estatisticamente significativas entre as freguesias foram visíveis em cinco dos sete testes aplicados: sentado e alcançar, levantar e sentar da cadeira, flexão do antebraço, sentado, caminhar $2,44 \mathrm{~m}$ e voltar a sentar e caminhar 6 minutos.

Petrica, Lima y Pereira (2008) realizaram um estudo com 30 idosas do género feminino, com o objetivo de descobrir se há diferenças significativas nas habilidades motoras entre idosos que praticam atividades física orientada e idosos que não praticam. Os principais resultados demonstraram que todas as habilidades motoras avaliadas relevaram valores significativamente melhores em idosos que praticam atividade física regular e orientada comparativamente com idosos que não praticam atividade física organizada.

Paulo y Brito (2012) realizaram um estudo com 90 idosos (26 Sedentários, 26 praticantes de AF não formal e 38 praticantes de AFO), com o objetivo de verificar os efeitos da prática de AF formal e não formal na melhoria da capacidade funcional e na composição corporal (IMC) da população idosa. Os principais resultados demonstraram que AF não formal tem efeitos na melhoria da capacidade funcional da população idosa. No entanto não se verificam melhorias na flexibilidade e na composição corporal, expressa pelo IMC, dos idosos com a prática não formal de AF. As atividades físicas supervisionadas e com objetivos quanto à intensidade e tipo de exercício, de forma continuada e regular, consolidam uma melhoria na capacidade 
funcional e no IMC do idoso, comparativamente à $A F$ não formal e ainda mais acentuadamente com indivíduos sedentários.

Podemos também referir que a freguesia de Pessegueiro apresenta diferenças estatisticamente significativas com três freguesias (Dornelas do Zêzere, Pampilhosa da Serra e Unhais-o-Velho) e a freguesia de Unhais-o-Velho apresenta diferenças estatisticamente significativas com cinco das sete freguesias restantes (Cabril, FajãoVidual, Janeiro de Baixo, Portela do Fojo-Machio e Pessegueiro).

\section{CONCLUSÕES}

Podemos constatar que a prática de atividade física organizada (Ginástica Sénior) teve um impacto positivo nos níveis de aptidão física dos idosos, tendo sido visíveis melhorias nas médias dos resultados em praticamente todos os testes aplicados, em comparação ao grupo de não praticantes de atividade física organizada. Pela análise dos resultados podemos concluir que existem diferenças significativas entre o grupo de idosos praticantes em relação ao grupo de não praticantes de AFO no parâmetro IMC e em todas as provas aplicadas da bateria de testes de Rikli y Jones (2001).

E nesse sentido aceitamos a Hipótese 1, há diferenças estatisticamente significativas na aptidão física funcional entre o grupo de idosos praticantes de atividade física organizada e o grupo de idosos não praticantes de atividade física organizada.

Podemos constatar que existem diferenças significativas na ApF entre as freguesias nos testes sentar e levantar da cadeira, levantar e sentar da cadeira, flexão do antebraço, sentado, caminhar 2,44m e voltar a sentar e caminhar durante 6 minutos. Essas diferenças foram observadas entre as freguesias de Pessegueiro e as freguesias de Dornelas do Zêzere, Pampilhosa da Serra e Unhais-o-Velho e a freguesia de Unhais-o-Velho com as freguesias do Cabril, Fajão-Vidual, Janeiro de Baixo, Portela do Fojo-Machio e Pessegueiro.

Encontrámos diferenças estatisticamente significativas em 5 das 7 provas aplicadas e nesse sentido rejeitamos a Hipótese 2, não há diferenças estatisticamente significativas em todos os parâmetros avaliados de aptidão física funcional dos praticantes de AFO entre as diferentes freguesias.

\section{REFERENCIAS}

Costa, D. (2007). Influência da Actividade Física na Aptidão Física de Idosos Institucionalizados e Não Institucionalizados. Porto: C. David. Dissertação de Licenciatura apresentada à Faculdade de Desporto da Universidade do Porto.

INE (2011). Recenseamento Geral da População e da Habitação. Recuperado: 20/02/2016 de http://mapas.ine.pt/map.phtml

INE (2014). Tábua Completa de Mortalidade no triénio 2011-2013 em Portugal. Recuperado: 20/02/2016 de http://pns.dgs.pt/files/2016/12/AnexoVla Esperanc\%CC\%A7a-de-vida-mais- 
elevada-a\%CC\%80-nascenc\%CC\%A7a-na-regia\%CC\%83o-Centro-e-aos-65$\underline{\text { no-Algarve.pdf }}$

INE (2015). Envelhecimento da população residente em Portugal e na União Europeia. Recuperado: $20 / 02 / 2016$

de https://www.ine.pt/xportal/xmain?xpid=INE\&xpgid=ine destaques\&DESTAQUE Sdest boui=224679354\&DESTAQUESmodo=2\&xlang=pt

INE (2016). 12." edição de "Península Ibérica em Números / Península Ibérica en Cifras". Recuperado: 21/02/2016 de http://www.aenfermagemeasleis.pt/2016/03/31/relatorio-peninsula-iberica-emnumeros-peninsula-iberica-en-cifras-2015-ine/

Paulo, R. (2010). A Actividade Física na População Idosa. Efeitos da Actividade Física não formal na Capacidade Funcional e no Índice de Massa Corporal, da População Idosa. Dissertação de Mestrado em Atividade Física, na Especialidade de Gerontomotricidade. ESE - Instituto Politécnico de Castelo Branco.

Paulo, R., y Brito, J. (2012). Efeitos da atividade física não formal na capacidade funcional e no índice de massa corporal, da população idosa. ÁGORA para la educación física y el deporte. ISSN 1989-7200. №14 (3), (pp. 348-358).

Petrica, J., Lima, N., y Pereira, S. (2008). A Actividade Física na terceira idade diferenças ao nível das habilidade motoras entre idosos que praticam actividade física e os que não praticam. In Livro Digital do $12^{\circ}$ Congresso de Educação Física e Ciências do Desporto dos Países de Língua Portuguesa. Porte Alegre, UFRGS, 17-20 setembro.

Rikli, E., y Jones, J. (2001). Senior Fitness Test Manual. Champaign, IL: Human Kinetics. 